\title{
Implantação de embalagens reutilizáveis na indústria automotiva: estudo de caso
}

\author{
Implementation of reusable packaging in the automotive industry: case study \\ Fabiano de Lima Nunes', Mauro Vinicius Rocha², Miguel Afonso Sellitto \\ 1, 2 Mestrando em Engenharia de Produção e Sistemas, UNISINOS, São Leopoldo, Brasil. \\ ${ }^{3}$ Professor e pesquisador do PPGEPS, UNISINOS, São Leopoldo, Brasil.
}

\section{Resumo}

Este artigo descreve um estudo de caso sobre a substituição de embalagens descartáveis por embalagens reutilizáveis no fluxo internacional de materiais em uma indústria de autopeças no Mercosul. O estudo diz respeito a peças automotivas exportadas do Brasil para a Argentina pelo modal rodoviário. Inicialmente, apresenta-se uma revisão teórica a respeito de logística reversa, embalagens retornáveis e logística internacional. A seguir descreve-se o caso, de acordo com as informações colhidas pelos pesquisadores junto à empresa estudada. Descrevem-se os fatos, investigam-se as causas que os originaram e compara-se o processo anterior ao que contempla a utilização de embalagens descartáveis, com um novo processo, baseado em embalagens retornáveis. O presente artigo visa responder a seguinte questão de pesquisa: como pode ser implementado um fluxo internacional de retorno de embalagens reutilizáveis na indústria automotiva? Expressivos ganhos econômicos, logísticos e ambientais foram observados.

Palavras-chave: Logística reversa, embalagens retornáveis, embalagens descartáveis, exportação, importação, fluxo reverso.

\begin{abstract}
This article describes a case study on the replacement of disposable packaging for reusable packaging in the international flow of materials in a auto parts company in the Mercosur. The study concerns the automotive parts exported from Brazil to Argentina by the road modal. Initially, it presents a theoretical review about reverse logistics, returnable packaging and international logistics. The following describes the case, according to the information collected by researchers at the company studied. Describe the facts, investigate the causes that originated and compares the process prior to that contemplates the use of disposable packaging, with a new process, based in returnable packaging. This article aims to answer the following research question: How can it be implemented an international flow of return reusable packaging in the automotive industry? Substantive economic, logistics, and environmental gains were yield.
\end{abstract}

Keywords: Reverse logistics, returnable packaging, disposable packaging, export, import, reverse flow. 


\section{INTRODUÇÃO}

Práticas de logística reversa (LR) têm se tornado importante fator gerador de vantagem competitiva, tanto como atividade formadora de imagem ambiental positiva, como atividade capaz de gerar resultados econômicos compensadores (DAUGHERTY et al., 2001). Produtos com ciclo de vida mais curtos, que foram rapidamente descartados por usuários, varejistas que não querem manter modelos antigos ou desatualizados em estoque, mercadorias danificadas que foram recebidas, transferências incorretas, e recalls de produtos são alguns dos motivos que justificam práticas de logística reversa (RITCHIE et al., 2000).

Não só aspectos econômicos interessam quando se planejam atividades de LR. Aspectos socioambientais relacionados à atividade também interessam (SRIVASTAVA e SRIVASTAVA, 2006). A Lei Federal 12.305, que instituiu a Política Nacional de Resíduos Sólidos, define logística reversa como um "instrumento de desenvolvimento econômico e social caracterizado por um conjunto de ações, procedimentos e meios destinados a viabilizar a coleta e a restituição dos resíduos sólidos ao setor empresarial, para reaproveitamento, em seu ciclo ou em outros ciclos produtivos, ou outra destinação final ambientalmente adequada" (PNRS, 2010). No entanto, objetivos econômicos ainda parecem ser os mais evidentes na implementação de programas de LR (GUNASEKARAN e SPALANZANI, 2012).

Apesar do crescente reconhecimento da importância da LR, muitas empresas podem enfrentar dificuldades no gerenciamento dos retornos. O rápido crescimento no volume de retornos pode superar a capacidade das empresas para gerenciá-lo (RUPNOW, 2007). Devido às incertezas envolvidas, o processo de gerenciamento dos fluxos de retorno pode se tornar um entrave à sua adoção (BOGATAJ e GRUBBSTRÖM, 2013). Um dos elementos presentes em fluxos de retorno, que é responsável por expressiva geração de resíduos sólidos, são as embalagens industriais. O uso de embalagens descartáveis gera expressivo volume de resíduos, o que contribui para a saturação dos aterros sanitários existentes e para eventual escassez de matérias-primas (GONZÁLEZ-TORRE et al., 2004).

Neste contexto, o objetivo deste artigo foi descrever a implementação de um fluxo reverso internacional de embalagens industriais reutilizáveis, implantado em uma empresa da indústria automobilística. A pergunta de pesquisa foi: como pode ser implementado um fluxo internacional de retorno de embalagens reutilizáveis na indústria automotiva? O método de pesquisa foi o estudo de caso. $\mathrm{O}$ objeto de estudo foi o fluxo de embalagens Brasil-Argentina, gerenciado por uma empresa da indústria automotiva, com operações nos dois países. Pesquisas anteriores foram consultadas e apoiaram este artigo: comparação entre embalagens retornáveis e descartáveis (SILVA et al., 2013); barreiras para implementação de LR (ABDULRAHMAN et al., 2012); gerenciamento de operações em LR (LEE e LAM, 2012), gerenciamento de fluxos reversos (SRIVASTAVA e SRIVASTAVA, 2006); gerenciamento da informação em LR (SHI et al., 2012); apoio à decisão em LR (LAMBERT et al., 2011); implementação de programas estruturados de LR (RICHEY et al., 2005); embalagens reutilizáveis em transporte internacional (ADLMAIER e SELLITTO, 2007); diagnóstico em LR (JANSE et al., 2009); e eficiência do transporte em LR (BOGATAJ e GRUBBSTRÖM, 2013).

O restante do artigo está organizado em: revisão, metodologia, resultados, discussão, e conclusões. Parte da pesquisa foi financiada pelo CNPq.

\section{REVISÃO}

Logística reversa é o processo de planejamento, implementação e controle de fluxo de matérias-primas, estoques em processo, produtos acabados e informações relacionadas, partindo do ponto de consumo em direção ao ponto de origem, com a finalidade de recapturar valor ou dar descarte adequado a bens que já foram vendidos a comerciantes, mas que não chegaram a ser consumidos, ou a resíduos de produtos que já foram usados pelo consumidor final (ROGERS e TIBBEN- LEMBKE, 2001). Fluxos de retorno constituem uma cadeia de suprimentos reversa, ou seja, um conjunto de atividades necessárias para recuperar valor remanescente de um produto que não foi vendido ou que já foi usado (GUIDE e VAN WASSENHOVE, 2002). Os principais canais reversos pelos quais resíduos e produtos podem retornar ao ciclo produtivo são a reciclagem, a remanufatura, o reuso, a reconstrução (refurbishing) e o reparo (SRIVASTAVA, 2008). A Figura 1 ilustra estes canais. 


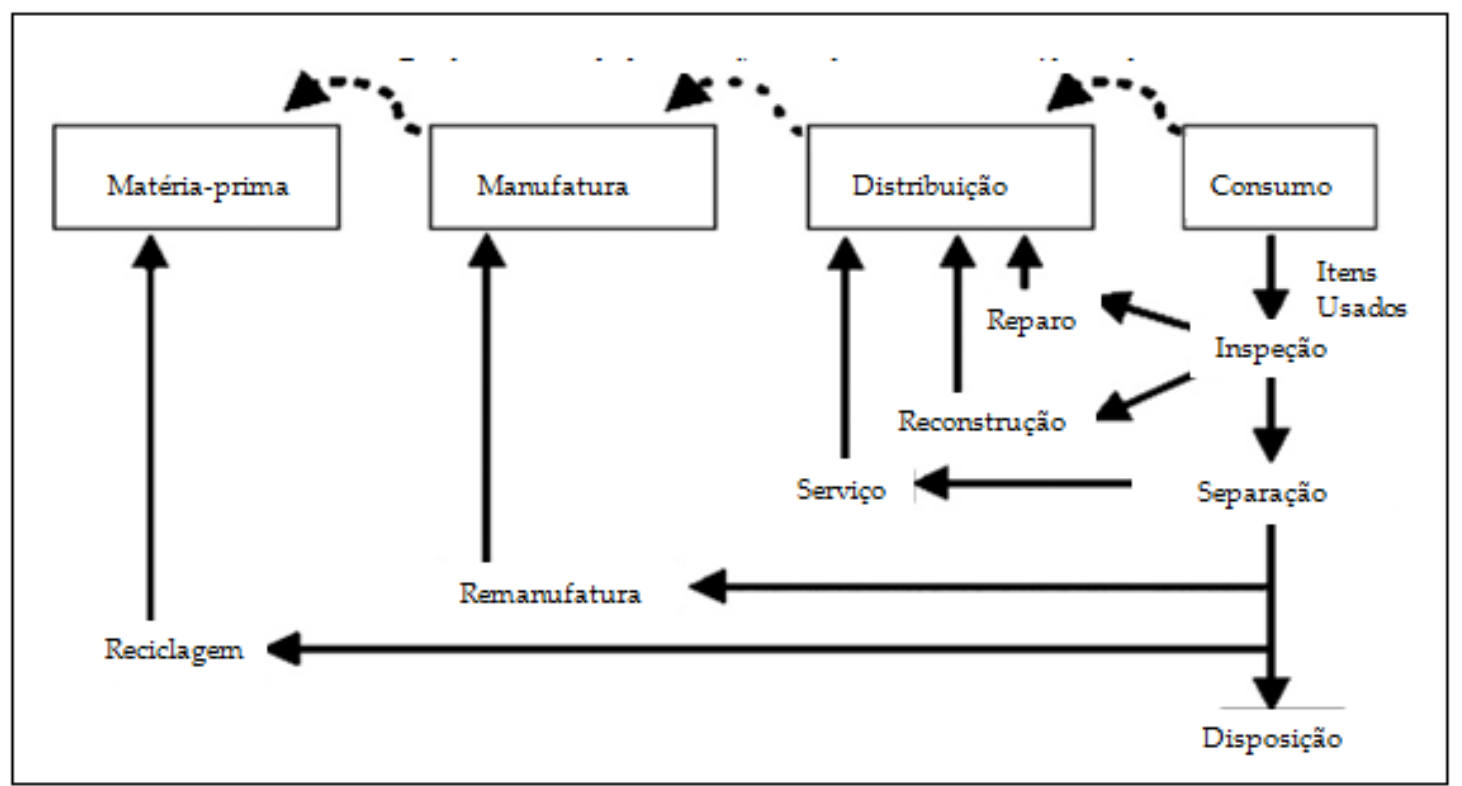

Figura 1: Canais reversos de recuperação de valor (adaptado de Srivastava, 2008).

Benefícios podem ser obtidos pela adoção de práticas de LR: retenção e satisfação de clientes; reutilização de embalagens; reciclagem, recuperação e reabastecimento de itens; redução de estoque de matérias-primas; recuperação de equipamentos obsoletos; ou venda em mercados secundários de itens em boa condição de uso (MOORE, 2005). Para Da et al. (2004) e Parvenov (2005), alguns problemas comuns relacionados à logística reversa são: armazéns pequenos ou mal definidos; incerteza em relação ao fluxo de retorno; dificuldade de rastreamento em tempo real, dificultando práticas de cross-docking; e alto custo comparado ao valor a ser recuperado, o que dificulta a viabilização de investimentos.

Um elemento importante em fluxos reversos são as embalagens industriais (ADLMAIER e SELLITTO, 2007). No mercado industrial, com o objetivo de reduzir custos, tem sido observado uso mais intenso de embalagens reutilizáveis ao invés de descartáveis (TWEDE e CLARKE, 2005). Para tanto, é importante desenvolver embalagens leves e resistentes, que custem pouco, otimizem a carga e previnam danos durante o transporte (DAE KO et al., 2011). Outra necessidade gerencial é a integração de rotas, já que embalagens reutilizáveis são transportadas na direção oposta à distribuição. Se ambas as tarefas são executadas pela mesma infraestrutura de transporte, um problema de roteamento surge, e sua solução deve considerar, simultaneamente, tanto a via direta como a reversa, definindo uma rota com entregas e coletas (DETHLOFF, 2001).

Além de benefícios econômicos e ambientais, o uso de embalagens reutilizáveis também acarreta alguns prejuízos (LEITE, 2009): maior custo unitário de transporte, dada a mais baixa densidade da embalagem vazia; necessidade de gerenciamento de um fluxo assimétrico (ida diferente da volta), necessidade de processamento da embalagem (recepção, armazenamento, limpeza, manutenção), e menor retorno do capital investido, dado o valor mais baixo remanescente no produto retornado.

O caso estudado envolve logística internacional, mais especificamente, no Mercosul. Neste caso, os principais desafios são a geografia ampla e complexa, como o litoral estendido, devido à junção das costas do Brasil, Uruguai e Argentina. De modo geral, há pouca utilização da navegação de cabotagem ou fluvial, e pouca integração das ferrovias, devido as diferentes bitolas de seus trilhos. Deste modo entende-se o elevado uso do modal rodoviário na região, marcado pela morosidade em processos burocráticos e perdas de tempos nas fronteiras (LARRÃNAGA, 2003). Com isto, o nível típico de serviço logístico observado é menor do que o observado em outras regiões e do que seria desejável no atual mercado de competição, característico da indústria automotiva (DANESI, 1997).

\section{METODOLOGIA}


O método de pesquisa foi o estudo de caso. O estudo de caso examina em profundidade um fenômeno contemporâneo, dentro de seu contexto, especialmente quando os limites entre fenômeno e contexto não são claramente de nidos e evidentes. Admite-se que, ao longo do estudo, os tópicos estudados possam ser reorganizados e recombinados segundo critérios emergentes (YIN, 2010). Para validade e confiabilidade dos resultados, foram consideradas múltiplas fontes de evidência: entrevistas, relatórios e documentação relacionada (GIBBERT e RUIGROK, 2010). Os entrevistados foram selecionados por sua capacidade de contribuição à pesquisa. Com base na revisão, foi estruturado um protocolo para orientar as entrevistas incluindo os seguintes elementos: logística reversa, embalagens reutilizáveis e logística internacional.

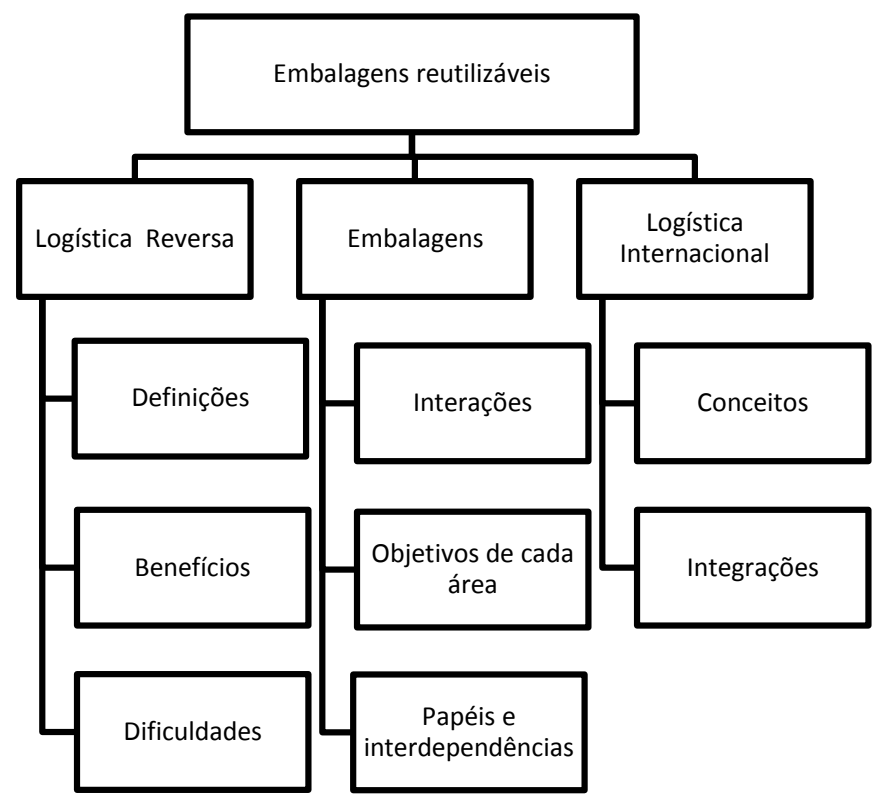

A Figura 2 apresenta a estrutura de protocolo de pesquisa desenvolvido.

Figura 2: Modelo de pesquisa

Foram entrevistados quatro gestores da empresa, diretamente ligados ao processo de exportação e importação entre Brasil e Argentina. Os entrevistados atuam nas áreas de Logística, Planejamento e Controle da Produção, Comércio Internacional e Comercial. As entrevistas duraram cerca de duas horas. Além disto, foram realizadas visitas técnicas na empresa com objetivo de conhecer melhor a operação e obter relatórios, indicadores, formulários, e demais documentos relacionados ao fluxo estudado. Os perfis dos entrevistados são apresentados no Quadro 1.

Quadro 1: Critérios para a seleção dos representantes pesquisados

\begin{tabular}{ccl}
\hline Entrevistado & Área & \multicolumn{1}{c}{ Critérios } \\
\hline A & Logística & $\begin{array}{l}\text { Responsável pelo desenvolvimento, implementação e controle do } \\
\text { uso de embalagens retornáveis nos fluxos nacional e internacional. } \\
\text { Responsável pela análise de pedidos e programação de produção } \\
\text { de todos os clientes nacionais e internacionais. } \\
\text { B }\end{array}$ PCP \\
C & Comércio & $\begin{array}{l}\text { Responsável pelo transporte internacional assim como todos os } \\
\text { tramites internacionais (documentações, desembaraço, registros } \\
\text { de importação e exportação, etc.). } \\
\text { Responsável pelas negociações comerciais que envolvam novos } \\
\text { projetos, investimentos em embalagens, etc. com clientes } \\
\text { nacionais e internacionais. }\end{array}$ \\
\hline Comercial
\end{tabular}




\section{RESULTADOS}

Inicialmente foi realizada uma análise individual dos resultados obtidos nas entrevistas. Os resultados destas análises foram cruzados de maneira a reunir todas as informações, oriundas das diferentes áreas pesquisadas. Após, foram feitas análises críticas dos documentos coletados e das observações feitas durante as visitas. A partir das informações obtidas pelos instrumentos de pesquisa, seguem, em forma de relato, a situação anterior e a nova situação, após a solução implantada. Os problemas verificados, as soluções adotadas e os benefícios gerados pela mudança são relatados e discutidos mais a frente.

A empresa estudada localiza-se em Porto Alegre e produz autopeças para as principais montadoras de veículos do Mercosul. O fornecimento brasileiro para o mercado argentino iniciou no final de 2011 em consequência do fechamento da filial local até então responsável pelo abastecimento. Inicialmente, visando manter o nível de atendimento aos clientes daquela região, optou-se pela utilização de embalagens descartáveis, cujo projeto estava consolidado por vários anos de operação doméstica bem sucedida.

A mudança para embalagens reutilizáveis foi motivada inicialmente pelos altos custos relativos a este tipo de embalagem, e que se mostraram maiores do que o previsto no escopo original. Outros pontos importantes também foram levados em consideração na elaboração do projeto de mudança: problemas ergonômicos de funcionários do embalamento, riscos de qualidade das peças no manuseio, geração de resíduos para o meio ambiente, baixo número de peças por volume, maior ocupação de espaço para armazenagem, perdas de embalagens por avarias na movimentação, maior número de movimentações entre almoxarifado e produção, etc. Devido a estes problemas, a empresa decidiu mudar o conceito de embalamento, passando a exportar em embalagens reutilizáveis. A motivação inicial, portanto, foi econômica, como observado pela literatura, mas também existiram outros motivadores.

As embalagens utilizadas até então eram compostas por: palete de madeira, caixa e tampa de papelão (Figura 3), bandejas internas de papelão, cintas plásticas de arquear, selos metálicos, fitas adesivas e sacos e lâminas VCI (Volatile Corrosion Inhibitors). Estes últimos eram utilizados devido à umidade absorvida pelo papelão, que pode atingir as peças. A embalagem escolhida para substituir as descartáveis foi a mesma já amplamente utilizada com os clientes do mercado nacional, composta quase totalmente de material plástico (Figura 4). As bandejas internas, termo formadas, são 100\% plásticas, não havendo necessidade de outro acessório interno, eliminando, entre outros, os sacos e lâminas VCI.

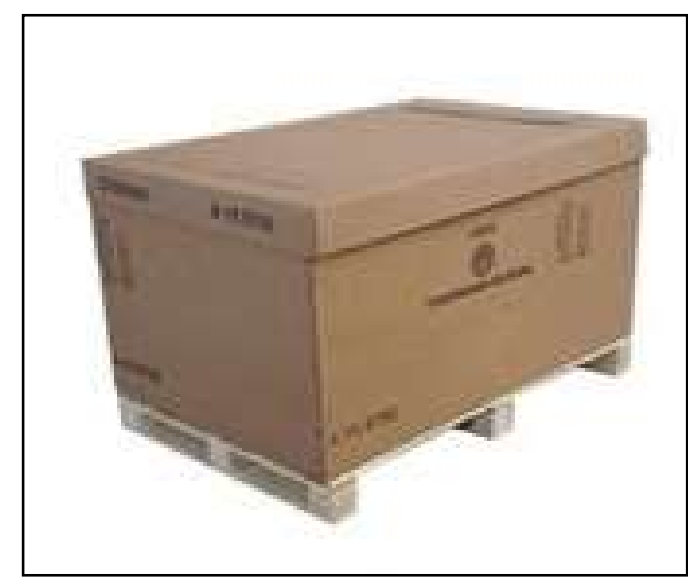

Figura 3: Caixa de papelão original Fonte: www.grupolumapack.com.br

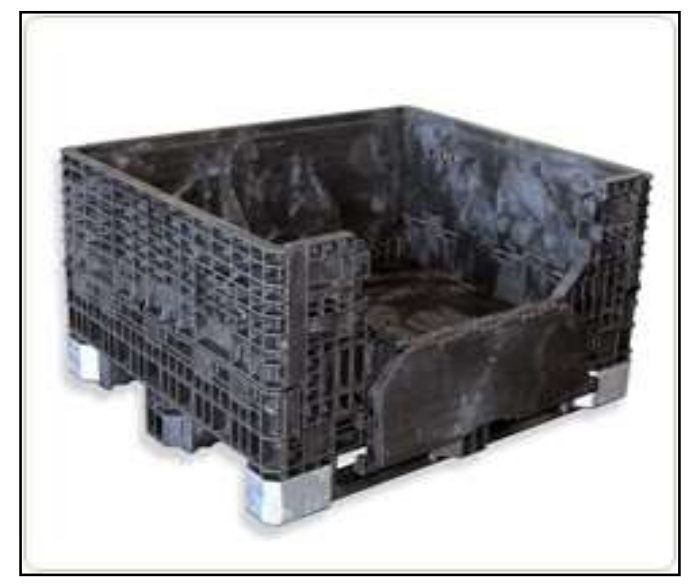

Figura 4: Caixa móbil introduzida Fonte: www.unipac.com.br

A nova embalagem tem vida útil estimada de cinco anos, não gera resíduo, e é facilmente reciclada. O número médio de peças por volume passou dos atuais 50 para 70 peças, o que equivale a um expressivo aumento de $40 \%$. A capacidade de empilhamento também sofreu alteração, passando de duas caixas de papelão para quatro do tipo móbil. Tais modificações trouxeram reflexos diretos no transporte pelo maior aproveitamento da cubagem do veículo e também no armazém, para o caso da 
armazenagem do tipo blocada. Outra diferença está nas aberturas laterais que facilitam o acesso para colocação e retirada manual das peças.

O envio de peças para os clientes na Argentina ocorre semanalmente e seu retorno com embalagens vazias ocorre a cada 15 dias. Isto ocorre devido às embalagens tipo móbil serem colapsáveis, ou seja, quando vazias reduzem de tamanho, dobrando-se sobre si mesmas. Com isto tem-se uma proporção de, a cada dois veículos enviados com peças, um veículo retorna com embalagens vazias. Para ambos os casos é utilizado o modal rodoviário. O veículo padrão neste tipo de operação é a carreta tipo sider com capacidade de carga de vinte e cinco toneladas.

Os clientes na Argentina estão localizados nas cidades de Buenos Aires, Rosário e Córdoba. A Tabela 1 resume os diferentes conceitos de embalagem. A Figura 5 representa o fluxo geográfico das embalagens.

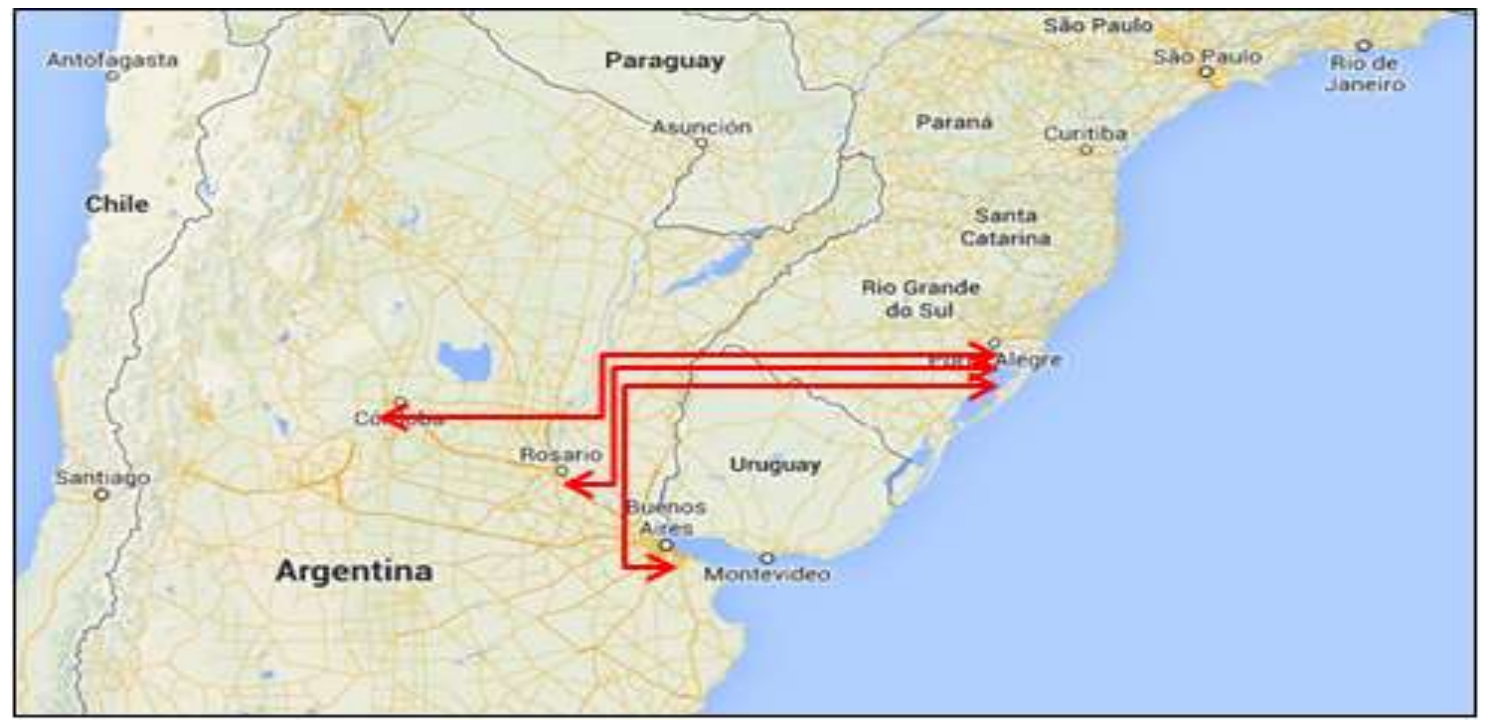

Figura 5: Representação do fluxo geográfico de embalagens

Fonte: Empresa

Para o cálculo da quantidade de embalagens necessárias, foram considerados os tempos das etapas do processo de exportação de peças, somados com o tempo de retorno da embalagem, o que resultou em um tempo médio total de trânsito de trinta dias. Este é o tempo médio entre a data de envio de uma embalagem para Argentina até o retorno ao Brasil e recolocação na linha de montagem. Neste tempo médio foram consideradas as variações que ocorrem nos processos de exportação e importação, principalmente nas aduanas brasileira e argentina.

\section{DISCUSSÃO}

A implantação começou pela aquisição das embalagens, em março de 2012. O tempo estimado para retorno do investimento para cada caso foi de 12 meses. A depreciação está estimada para ocorrer em três anos e o tempo previsto de duração das embalagens é de cinco anos. Após os primeiros meses de operação, a redução de gastos observada foi de cerca de $\mathrm{R} \$ 800.000$ por ano. Para os próximos períodos, as estimativas são as mesmas, porém os resultados poderão variar de acordo com os volumes de produção, custos de transporte, custos aduaneiros, entre outras variabilidades esperadas no processo.

\section{I DiFICULDADES NA IMPLANTAÇÃo} culturais.

Foram identificados quatro tipos de dificuldades: comerciais, operacionais, documentais, e

As dificuldades comerciais foram no investimento nas embalagens, responsabilidade no transporte, responsabilidade pelo desembaraço, e custo de reposição. As dificuldades operacionais foram 
no gerenciamento do fluxo, limpeza, manutenção, identificação, e otimização e aproveitamento da carga. As dificuldades documentais foram na fatura comercial, ato concessório, certificado de origem, conhecimento de transporte rodoviário, declaração de transito aduaneiro, e manifesto internacional de carga. Por fim, a dificuldade cultural foi no idioma.

\subsection{SOLUÇõES ADOTADAS}

Para solucionar as dificuldades, a empresa fornecedora de peças localizada no Brasil tomou algumas ações. No primeiro momento foram realizadas visitas sistemáticas à Argentina visando identificar as barreiras existentes pelos clientes para implantação do projeto. Nas visitas subsequentes, houve apresentações estruturadas para as áreas envolvidas (Logística, Compras, Comercial e Comércio Exterior) sobre os benefícios para ambas as empresas pela adoção de embalagens retornáveis.

No passo seguinte iniciou-se a fase de negociações comerciais, que mostrou-se ser uma das mais demoradas do processo. Depois de algumas rodadas de negociação, optou-se pela aquisição de embalagens pelo fornecedor de peças, assim como sua manutenção e reposição quando necessário. A responsabilidade do frete no retorno de embalagens ficou com o fornecedor, que já possuía o frete de entrega de peças e assim poderia conseguir um frete mais competitivo. O desembaraço das peças permaneceu nos clientes devido às aduanas dentro das plantas. O desembaraço de embalagens ficou com o fornecedor, ficando este último com os ganhos financeiros futuros do projeto.

A próxima etapa incluiu os acertos operacionais necessários para o bom andamento das atividades. Diversos e-mails foram trocados entre os envolvidos, detalhando questões de transporte, empilhamento, otimização de carga, identificação, manuseio, ou diferenciação dos tipos de embalagens, ou seja, envolvendo quase todo o gerenciamento do fluxo de ida e vinda de embalagens. Visitas operacionais também foram realizadas visando um melhor entendimento de ambas as partes sobre a operacionalização do projeto.

O último ponto abordado foram as questões relativas às documentações necessárias para os processos de exportação e importação. $O$ fato de os clientes possuírem aduanas em suas plantas facilitou este processo. Validações de documentações foram feitas antecipadamente, evitando novos problemas após o início do novo fluxo.

\subsection{GANHOS}

Quatro tipos de ganhos foram observados: econômicos, operacionais, ambientais, e ergonômicos.

O ganho econômico foi a redução anual de cerca de $\mathrm{R} \$ 800.000$, composta por redução no custo de transporte por peça; melhor aproveitamento do armazém, redução de funcionários na área de embalamento, e aumento da produção de peças por hora por funcionário. Os ganhos operacionais foram: redução de movimentações com equipamentos; maior capacidade de armazenagem devido ao maior empilhamento, menor número de movimentos dos operadores nas células de produção, redução da etapa extra de embalamento e de problemas de qualidade devidos a manuseios adicionais. Os ganhos ambientais foram: eliminação de resíduos de papelão (caixas e bandejas internas), de resíduos plásticos (saco e lâminas VCI e fitas de arquear) e metálicos (selo metálico), redução do número de veículos com emissão de poluentes, e reciclagem das caixas plásticas após vida útil. Por fim, os ganhos ergonômicos foram: caixa móbil com acesso lateral para colocação e retirada de peças, maior facilidade na colocação e retirada das peças das bandejas internas, e menor número de movimentos dos operadores nas células de produção. O Quadro 2 sintetiza os resultados, segundo o modelo.

Quadro 2: Resultados da Pesquisa.

\begin{tabular}{ccc}
\hline Constructo & Ganhos & Dificuldades \\
\hline Logística Reversa & Econômicos / Ambientais & Comerciais \\
Embalagens & Operacionais/ Ergonômicos & Operacionais \\
Logística Internacional & Comércio exterior & Culturais / Documentais \\
\hline
\end{tabular}




\section{CONCLUSÕES}

O objetivo deste artigo foi descrever a implementação de um fluxo reverso internacional de embalagens industriais, implantado em uma empresa da indústria automobilística. O método foi o estudo de caso.

As principais conclusões do estudo foram: como previsto pela literatura (GUNASEKARAN e SPALANZANI, 2012), a principal motivação para a adoção de embalagens reutilizáveis foi econômica. No entanto, como também apontado pela literatura (ADLMAIER e SELLITTO, 2007), outros ganhos foram observados: ganhos ambientais e operacionais. O retorno financeiro foi estimado em um ano, o que foi confirmado pelos ganhos até agora observados. A depreciação das embalagens ocorrerá em três anos e sua substituição está prevista para ocorrer em cinco anos.

A pesquisa apontou sugestões de continuidade: avaliação quali-quantitativa dos benefícios ergonômicos oferecidos pela nova embalagem; avaliação quantitativa dos tempos de fluxo do processo, incluindo as variabilidades; e avaliação formal do impacto ambiental, por instrumento do tipo pegada ecológica, das modificações inseridas no fluxo de embalagens.

\section{REFERÊNCIAS}

ADLMAIER, D.; SELLITTO, M. Embalagens retornáveis para transporte de bens manufaturados: um estudo de caso em logística reversa. Produção, v.17, n.2, p.395-406, 2007.

BOGATAJ, M.; GRUBBSTRÖM, R. Transportation delays in reverse logistics. International Journal of Production Economics, v.143, n.2, p.395-402, 2013.

DA, Q.; HUANG, Z.; ZHANG, Q. Current and future studies on structure of the reverse logistics system: a review. Chinese Journal Management Science, v.12, n.1, p. 131-138, 2004.

DAE KO, Y.; NOH, I.; HWANG, H. Cost bene $\square$ ts from standardization of the packaging glass bottles. Computers \& Industrial Engineering, v.62, n.3, p. 693-702, 2011.

DANESI, L. Nível de Serviços logísticos no transporte rodoviário internacional de produtos industrializados entre o Rio Grande do Sul e a Argentina. Dissertação de Mestrado - Universidade Federal do Rio Grande do Sul (UFRGS), Escola de Administração, Programa de Pós-Graduação em Administração, Porto Alegre,1997.

DAUGHERTY, P.; AUTRY, C.; ELLINGER, A. Reverse logistics: The relationship between resource commitment and program performance. Journal of Business Logistics, v.22, n.1, p.107- 123, 2001.

DETHLOFF, J., Vehicle routing and reverse logistics: the vehicle routing problem with simultaneous delivery and pick-up. OR Spectrum, v. 23, n. 1, p. 79-96, 2001.

GIBBERT, M.; RUIGROK, W. The "What" and "How" of Case Study Rigor: Three Strategies Based on Published Work. Organizational Research Methods, v.13, n.4, p.710-737, 2010.

GUIDE, D.; VAN WASSENHOVE, L. The reverse supply chain. Harvard Business Review, v.80, n.2, p.25$26,2002$.

GONZÁLEZ-TORRE, P.; ADENSO-DÍAZ, B., ARTIBA, H. Environmental and reverse logistics policies in European bottling and packaging firms. International Journal of Production Economics, v.88, n.1, p. 95-104, 2004.

GUNASEKARAN, A.; SPALANZANI, A. Sustainability of manufacturing and services: Investigations for research and applications. International Journal of Production Economics, v.140, n. 1, p. 35-47, 2012.

JANSE, B.; SCHUUR, P.; BRITO, M. A reverse logistics diagnostic tool: the case of the consumer electronics 
industry. The International Journal of Advanced Manufacturing Technology, v.47, n.5-8, p. 495-513, 2009.

LAMBERT, S.; RIOPEL, D.; ABDUL-KADER, W. A reverse logistics decisions conceptual framework. Computers \& Industrial Engineering, v.61, n.3, p. 561-581, 2011.

LARRÃNAGA, F. A gestão logística global. São Paulo: Aduaneiras, 2003.

LEE, C.; LAM, J. Managing reverse logistics to enhance sustainability of industrial marketing. Industrial Marketing Management, v.41, n.4, p. 589-598, 2012.

LEITE, P. Logística reversa: meio ambiente e competitividade, São Paulo: Prentice Hall, 2009.

MOORE, R. Reverse logistics-the least used differentiator. UPS Supply Chain Solutions, 2005.

RICHEY, G.; CHEN, H.; GENCHEV, S.; DAUGHERTY, P. Developing effective reverse logistics programs. Industrial Marketing Management, v.34, n.8, p. 830-840, 2005.

PARVENOV, L. Expert Insight: Best Practices in Warehouse Returns. Supply Chain Digest, 2005.

PNRS. Política Nacional de Resíduos Sólidos, 2010, disponível em http://www.mma.gov.br/port/conama/ legiabre.cfm?codlegi=636, acesso em março de 2014.

RITCHIE, L.; BURNES, B.; WHITTLE, P.; HEY, R. The benefits of reverse logistics: The case of the Manchester royal infirmary pharmacy. Supply Chain Management: An International Journal, v.5, n.5, p. 226- 233, 2000.

ROGERS, D.; TIBBEN-LEMBKE, R. An examination of reverse logistics practices. Journal of Business Logistics, v. 22, n.2, p.129-148, 2001.

RUPNOW, P. Using reverse logistics standards to improve your operations. Reverse Logistics Association News Letter, v. 34, n.1, 2007.

SHI, X.; LI, L. X.; YANG, L.; LI, Z.; CHOI, J. Y. Information flow in reverse logistics: an industrial information integration study. Information Technology and Management, v.13, n.4, p. 217-232, 2012.

SILVA, D; RENÓ, G.; SEVEGNANI, G.; SEVEGNANI, T.; TRUZZI, O. Comparison of disposable and returnable packaging: a case study of reverse logistics in Brazil. Journal of Cleaner Production, v.47, n.3, p.377-387, 2013.

SRIVASTAVA, S.; SRIVASTAVA, R. Managing product returns for reverse logistics. International Journal of Physical Distribution and Logistics Management, v.36, n.7, p. 524-546, 2006.

SRIVASTAVA, S. Network design for reverse logistics. Omega, v.36, n.4, p. 535-548, 2008.

SUBRAMANIAN, N. Critical barriers in implementing reverse logistics in the Chinese manufacturing sectors. International Journal of Production Economics, v.147, Part B, p.460-471, 2014.

TWEDE, D., CLARKE, R. Supply chain issues in reusable packaging. Journal of Marketing Channels, v.12, n. 1, p.7-26, 2004

YIN, R. Estudo de caso: planejamento e métodos. $4^{\mathrm{a}}$ Ed. Porto Alegre: Bookman, 2010. 